\title{
A Review on Phytochemical constituents of Abutilon indicum (Link) Sweet - An Important Medicinal Plant in Ayurveda
}

\author{
${ }^{\mathrm{I}}$ Suryawanshi Venkat S. and ${ }^{2}$ Umate Suvarna R.
}

${ }^{\text {I}}$ Department of Chemistry, P.G. and Research Centre, Shri Chhatrapati Shivaji College, Omerga. Dist. Osmanabad

${ }^{2}$ Department of Botany, Adarsh College, Omerga, Dist. Osmanabad (MS), India

Corresponding Author: suvarnavsurya@gmail.com

Manuscript Details

Manuscript Submitted : 12/05/2020

Manuscript Revised : :13/05/2020

Manuscript Accepted : 14/05/2020

Manuscript Published : 20/05/2020

\section{$\underline{\text { Available On }}$}

https://plantaescientia.com/ojs

\section{Cite This Article As}

Surywanshi V. S. \& S S. R. Umate, (2020). A review on Phytochemical constituents of Abutilon indicum (Link) Sweet - An important medicinal plant in Ayurveda., Pla. Sci. 2020; Vol. 03 Iss. 03:15-19. DOI: https://doi.org/10.32439/ps.v3i3.15-19

\section{Copyright}

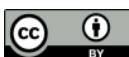

(c) The Author(s). 2018. Open Access This article is distributed under the terms of the Creative Commons Attribution 4.0 International License http://creativecommons.org/licenses/by/4.0/

$\underline{\text { Indexed In }}$

Crossref,Index Copernicus International (ICI), Directory of Research Journal Indexing (DRJI), Scientific Indexing Services

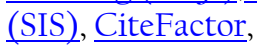

\section{ABSTRACT}

Abutilon indicum (Link) Sweet is a medicinal shrub belonging to the family Malvaceae; It has been extensively used as a traditional medicine to cure different diseases. It is considered invasive on certain tropical islands. The plant is very much used in Ayurveda \& Siddha medicines in Tamilnadu. In fact, the bark, root, leaves, flowers and seeds are all used for medicinal purposes. The phytochemical analysis showed the Presence of alkaloid, saponins, amino acid, flavonoids, glycosides and steroids. Some important essential oil constituents like $\alpha$-pinene, mucilage, tannins, caryophyllene, asparagines, caryophylleneoxide, endesmol, farnesol, borenol, geraniol, geranyl acetate, elemene and $\alpha$-cineole have been reported from plant. Phytoconstituents like $\beta$-Sitosterol, caffeic acid, fumaric acid, vanillin, p-coumaricacid, p-hydroxybenzoic acid, sesquiterpene including lactones, alantolactone and isoalanto-lactone along with this hexoses, $\mathrm{n}$-alkane mixtures $\left(\mathrm{C}_{22-34}\right)$, alkanol, gallic acid also been reported from different part of the plant. The present paper provides detailed review of literature on the phytochemical properties of $A$. indicum (Link) Sweet, which may be helpful to establish effective and useful natural drugs for further research.

Keywords: Pharmacology, Glycosides, traditional medicine, Abutilon indicum (Link) Sweet, phytochemical analysis. 


\section{INTRODUCTION}

People not only depend on plants for several purposes like for wood, timber, non-timber forest products, food but also plants have been used as medicines for thousands of years (Jain etal2005) as natural drugs are effective in action without side effects. Botanically, Abutilon Indicum (Link) Sweet (also called Indian mallow in English and Atibala in Hindi) is an Indian medicinal plant used in Ayurveda. A. indicum (Link) Sweet is a hairy under-shrub with golden yellow flowers, found in the outer Himalayan tracts from Jammu to Bhutan up to an altitude of $1500 \mathrm{~m}$ and extending through the whole of northern and central India. It can grow in dry and poor soil andrequire hot conditions. In India it is very common on roadsides and waste places generally to grow after the rainy season.

The Abutilon indicum (Link) Sweet under the family Malvaceae includes 75 genera and 1000 species mostly confined to the tropical and sub-tropical regions of the world. In India the family is represented by 22 genera and about 110 species occurring mostly in the warmer part (Khanduri et al. 2014). Abutilon indicum (Link) Sweet is an important medicinal plant used in our traditional system of medicine to treat various health aliments (Vadnere et al. 2013). The plant is very much used in Siddha medicines. All the parts of plant have medicinal uses (Saraswathi et al. 2011). The bark and the root are used as a diuretic, anthelmintic, pulmonary sedative and in fever (Kashmiri et al. 2009). This plant is very much used in Siddha medicines. In fact, the bark, root, leaves, flowers and seeds are all used for medicinal purposes by Tamils. The leaves are also used to treat for pile complaints. The flowers are traditionally used to increase semen in men. The seeds from this plant are considered to be aphrodisiac and can be used for urinary disorders (Kirtikar et al. 1980), laxative for those having hemorrhoids and in the treatment of coughs, puerperal disease, urinary disorders, chronic dysentery, and fever (Jayaweera et al. 1982 and Thongsiri et al. 2001). Leaves are used as a remedy for piles and as demulcent tonic. A decoction of A. muticumis used in bronchitis, catarrhal bilious diarrhoea, gonorrhoea, inflammation of the bladder and fever (Ali et al. 2009). The flowers and leaves are used as a local application to boils and ulcers (Mhasker et al. 2000). Seeds are also used as diuretic and demulcent (Vaghasiya et al. 2007). The seeds cakes are used for dairy cattle and fertilizer (Gutkin et al. 1950). This plant shows antiinflammatory (Rajurkar et al. 2009), Lipid lowering (Giri et al. 2009), analgesic (Goyal et al. 2009), hepato-protective (Porchezhian et al. 2005), hypoglycemic (Seetharam et al. 2002), antimycotic(Rajalakshmi et al. 2009), anti-diarrhoeal (Chandrashekhar et al. 2004), anti-convulsing (Golwala et al. 2010), Larvicidal (Rahuman et al. 2008), Wound healing (Roshan et al. 2008), Anti asthmatic (Paranjape et al. 2006 and Paranjape et al. 2008), Diuretic (Balamurugan et al. 2010), Immune-modulatory (Dashputre et al. 2010), anti-estrogenic (Johri et al. 1991), In-vitro anti-arthritic (Deshpande et al. 2009) activities. A large number of plants still remain unexplored with regard to their medicinal properties and they can also be sources of potentially active compounds for the development of new drugs to treat various diseases. Considering the broad pharmacological applications there is a need to review on phytochemical constituents available in literature on Abutilon indicum (Link) Sweet to answer the gaps between ethnomedicinal uses and phytochemical studies, so that it would aid future research by phytochemists, pharmacologists, clinicians, researchers, scientists and toxicologists.

\section{Abutilon indicum (Link) Sweet (MALVACEAE)}

(Vernacular Names : Hindi - Kanghi, Kakahi; English Country mallow, Indian mallow; Bengali - Petari; Malayalam - Dabi, Uram; Guajarati - Khapat, Kansi, Dabli Marathi - Mudra, Petari ; Tamil -Tutti, Paniara, Hutti; Telugu -Tutturubenda)

\section{Plant Morphology}

Abutilon indicum (Link) Sweet is herbaceous weed. The stem of the plant is stout, branched. The stem of the plant is yellow and often found tinged with purple colour. The leaves are ovate, acuminate, toothed, rarely sub trilobite. The flowers are yellow in color, peduncle jointed above the middle, they are axillary solitary, jointed very near the top The fruits are capsule, densely pubescent, with conspicuous and horizontally spreading beaks. The seeds are $-5 \mathrm{~mm}$ in size, reniform, tubercled or minutely stellatehairy, black or dark brown (Kirtikar et al. 1994, Prajapati et al. 2003, Nadkarni 1995). The root of the plant is with smooth surface, cylindrical, fragrant, salty taste and yellow in color.

\section{Phytochemistry}

Abutilon indicum (Link) Sweet has been explored phytochemically by various researchers and found to possess number of chemical constituents.

A) Phyto-constituents from Root: In 2009Rajurkar et al. have reported the phyto-constituents from root which is non-drying oil which consists different fatty acids like linoleic, oleic, stearic, palmitic, lauric, myristic,caprylic, capric and unusual fatty acid having $\mathrm{Cl} 7$ carbon skeleton from which unsaponifiable matter were yielded. Recently in 2013, Amit et al. has reported beta sitostrol and amyrin from root extracts. 
B) Phytoconstituents from Flower: Various Flavonoids have been isolated from extract of flower (Sharma et al. 2013 \& Padma et al. 2009) it includes Quercetin-3-O- $\beta$-Dglucopyranoside, Luteolin-7-O- $\beta$-glupyranoside and Quercetin-3-0- $\alpha$-rhamnopyranosyl (1-6)- $\beta$-glucopyranoside (Matlawska et al. 2002), Gossypetin-7and 8-O- $\beta$ glucoside from flower petals(Subramanian et al. 1972) and also found luteolin ,Chrysoeriol, Chrysoeriol-7-O- $\beta$-glupyranoside, Apigenin-7-O- $\beta$-glupyranoside,Cyanidin-3-O-rutinoside.

C) Phyto-constituents from Leaves: Padma et al. in 2009 founded the various Steroids from the leaf extract of $A$. indicum (Link) Sweet. Macabeo et al. (2014) and Rahuman et al. (2008) extracted various sterols from leafs they are $\beta$ Sitostrol, cholesterol and stigmasterols (Rajput et al. 2012).Quercetin is important flavnol found in leaf extract (Rajput et al.2012). There are certain flavones observed in this plant they are Luteolin,Luteolin-7-O- $\beta$-glupyranoside ,Chrysoeriol, Chrysoeriol-7-O- $\beta$-glupyranoside (Singh et al .2008). Phenolic acid derivatives like Eudesmic acid, Ferulic acid (Rajput et al. 2012) and Caffeic acid (Pandey et al. 2011) also successfully obtained from methanol extract. $\beta$ Amyrin-3-palmitate is the main triterpenes present in leaf extract (Macabeo et al. 2014) and also founded squalene is major phytoconstituent from quinones.

D) Phytoconstituents from fruit: Sidharthet al.2016 showed that the compounds 2-Pentanone, 4-hydroxy-4methyl- seems to be most stable compound. Benzene, 1, 3 dimethyl (m-xylene), p-xylene and o-xylene were identified at retention time 6.44 with highest probability. Three compounds c-sitosterol, a-sitosterol and Cholest-5-en-3-ol, 4, 4-dimethyl- were identified. Three compounds Lupeol, Lup-20(29)-en-3-ol, acetate, and 9,19-Cyclo-9a-lanostane3a,25-diol were found in good stability and high probability.

E) Phytoconstituents from seed: Padma et al. (2009) foundcis 12, 13-epoxyoleic (vernolic) acid, 9, 10-methylene octadec-9-enoic(sterculic) acid, as well as 8, 9-methyleneheptadec-8-enoic (malvalic) acid, Stearic acid,palmitic acid threonine, glycine, serine, glutamine, lysine, methionine, isoleucine, proline, alanine, cystenine, tyrosine, phenylalanine, leucine, aspargine, histidine, valine, argininine in seed extract. Nithyatharani et al. (2018) performed qualitative analysis of the seed of Abutilon indicum and found positive tests for presence of alkaloids, steroids, terpenoids, flavonoids, saponins, phenols, cardiacglycosides, aminoacids, proteins, carbohydrates and reducing sugars from seed extract of various solvents.
F) Phytoconstituents fromstems: Prabhuji et al. (2010) successfully extracted 20, 23-Dimethylcholesta-6, 22-dien$3 \beta$-ol from stems.

G) Phytoconstituents from Aerial parts: Yasmin (2008) have found phenolic acid derivatives like $\mathrm{P}$ Hydroxybenzoicacid; sterols like , $\beta$-Sitostrol. They found flavonols 4',6-Dimethoxy kaempferol, 3,5,5'-Trihydroxy-4' methoxy flavone-7-O- $\beta$-D glucopyranoside and also confirms presence of triterpenesviz. $\beta$-Amyrin and Lupeol. They have also searched Vasicine as an alkaloid and amides along with waxes Methyl triacontanoate. Other phenolic acid like Glucovanilloylglucose (Gaind et al. 1976), Gallic acid (Amit et al. 2013) 4-O- $\beta$-Glucosylbenzoic acid, Caffeic acid, Fumaric acid and P-Coumaric acid have been isolated from aerial part of plant.

H) Phytoconstituents from whole plant: Mucilaginous substances, asparagine, saponins, flavonoids, alkaloids have been isolated from whole plant (Sharma et al. 2013). Kumar et al. (2008) found that there is presence of various sterols $\beta$-Sitostrol, $\beta$-Sitostrol-3-O- $\beta$-D-glucopyranoside along with phenolic acid derivatives Benzoic acid, Hydroxybenzoic acid, Stigmasterol, Benzoic acid, Caffeic acid, 4 Hydroxyacetophenone, 4-Hydroxybenzaldehyde,Vanillin and Syringaldehyde. The phytochemical screening of whole extracts of Abutilon indicum showed the presence of $\beta$ Sitostrol-3-O- $\beta$-D-glucopyranoside as sterols, they have also found phenolic acid derivatives likeMethyl-4 hydroxybenzoate and 2,6-Dihydroxy-4methoxyacetophenone. (24R)-5 $\alpha$ Stigmastane-3,6 dione, and 4-O- $\beta$-Glucosyls benzoic acid, Vanillic acid 4Hydroxyacetophenone, Hydroxybenzaldehyde, Vanillin, Syringaldehyde, Methyl-4-hydroxybenzoate, and Abutilin A. Extract of whole plant have oleanic acid as triterpenes. Various Quinones 2,6-Dimethoxy-1,4 benzoquinone was observed along with Coumarins founded are Scoparone, Scopoletin and 3,7-Dihydroxychromen-2-one.(Liu et al 2009, Kuo et al. 2009). Kuo et al. (2009) have studied on alkaloids and amides which are Aurantiamide acetate, (R) N-(l'-Methoxycarbonyl-2'-phenylethyl)-4-

hydroxybenzamide, N-Feruloyl tyrosine, 1-Lycoperodine, 1Methoxycarbonyl- $\beta$-carboline, Methyl indole-3carboxylate found in whole plant extract. Kuo et al (2009) also founded ionones they are 3-Hydroxy- $\beta$-damascone, 3 Hydroxy- $\beta$-ionol.Lactones studied was Alantolactone and Isoalantolactone; it also contains Vitamins Riboflavin along with nitrogenous bases Adenosine, Adenine and Thymine. Ali et al. (2009) extracted Quercetin as flavnols from whole plant. Yasmin (2008) have isolated and studied on phenolic acid derivatives4-O- $\beta$-Glucosyls benzoic acid,2,6 Dihydroxy-4-methoxyacetophenone and Quercetin as 
flavnols. Pandey et al. (2011), Gaind et al. (1976) searched phytochemicals; they are phenolic acid derivatives2,6Dihydroxy-4-methoxyacetophenone, Caffeicacid,4Hydroxy-3-methoxy-E-cinnamic acid methyl ester, Methyl 4-hydroxyphenylacetate, Methylcoumarateandvarious, Lactones found are Alantolactone and Isoalantolactone (Sharma et al. 1989)

\section{CONCLUSION}

The systematic survey literature reviewed that Abutilon Indicum (Link) Sweet, is an important medicinal plant with diverse pharmacological spectrum. Lot of phytochemical studies has been carried out with extract of the different parts of the plant. The present review summarizes important phytochemical investigations and isolated principles on Abutilon Indicum (Link) Sweet, which can be investigated further to achieve lead molecules in the search of novel herbal drugs. Due to medicinal properties there is enormous scope for future research on Abutilon Indicum(Link) Sweet and further clinical and pharmacological investigation should be conducted to investigate unexploited potential of this plant. Abutilon Indicum (Link) Sweethas many more pharmacological properties like; the main chemical constituents are carbohydrates, steroids, glycosides, flavonoids, tannins and Phenolic compounds. Hence this review article, effort has been taken to collect and compile the details notes on Abutilon Indicum (Link) Sweet which will be useful to the society to venture into a field of alternative systems of medicine.

\section{REFERENCES}

Ali S.,Yasmeen S., Afza N., Malik A., Iqbal L., Lateef M., Riaz N. (2009). Newantioxidant phenolic glucoside from Abutilion muticum. Asian Nat Prod Res.11 (5): 457-464.

Amit K. and Gyanender S. (2013). Determination of the bioactive components of Abutilon indicum, International Journal of Pharmacy and Biological Sciences4(4):898-901.

Balamurugan G., Selvarajan S., Dhanapal B. and Muralidharan P.,(2010). Diuretic activity of Abutilon indicum Linn. (Sweet) Seed Extract. J. Herbal Med. Toxicol.,4(1):49-52.

Chandrashekhar V. M., Nagappa A. N., Channesh T. S., Habbu P. V. and Rao K. P. (2004).Anti-Diarrhoeal Activity of Abutilon indicum Linn Leaf Extract. J. Natural Remedies. 4(1):12-16.

Dashputre N. L. and Naikwade N. S. (2010). Immunomodulatory activity of Abutilon Indicum linn. on albino mice. Int. J. Pharma Sci.Res.1(3):178-184.

Deshpande V.,Jadhav, V.M. and Kadam V.J. (2009). In-vitroanti-arthritic activity of Abutilonindicum (Linn.) sweet. J.Pharma Res.,2(4): 644-645.

Gaind K. N. and Chopra K. S. (1976). Phytochemical investigation of Abutilon indicum. Planta Medica.30:174-185.

Giri R. K., Kanungo S. K., Patro V. J., Das S. and Sahoo D.C.,(2009). Lipid lowering activity of Abutilon indicum (L.) leaf extracts in rats.J.Pharmacy Res.,2(11):1725-1727.
Golwala D.K., Patel L.D., Vaidya S.K.,Bothara S.B., Mani M. and Patel P. (2010). Anticonvulsant activity of Abutilon indicum leaf,Int. J. Pharmacy Pharma Sci.,2(1):66-71.

Goyal N., Singh S. and Sharma S. (2009). Analgesic effects of various extracts of the root of Abutilon indicum Linn, J. Pharm.BioAllied Sci.,1(1):43-46.

Jain A., Katewa S. S., Galav P. and Sharma P. (2005). Medicinal plantdiversity of Sitamata wildlife sanctuary Rajasthan, India.Journal of Ethnopharmacology,102:143-157.

Jayaweera DMA, (1982). Medicinal plants (Indigenous and Exotic) used in Ceylon. Part IV Magnoliaceae-Rubiaceae.,The national science council of Sri Lanka: Columbo: 9.

Johri R. K., Pahwa G. S., Sharma S. C. and Zutshi U. (1991) Determination of estrogenic/antiestrogenic potential of antifertility substances using rat urine peroxidase assay.Contraception, 44(5):549-557.

Kashmiri M.A., Yasmin S., Ahmad M. and Mohy-ud-Din A. (2009) Characterization, Compositional Studies, Antioxidant and Antibacterial activities of Seeds of Abutilon indicum and Abutilon muticum Grown Wild in Pakistan.ActaChimSlov.,; 56:345-352.

Khanduri N.C. (2014). Fertility Control of Female Rat through Abutilon Indicum Seeds. International Journal of Tech. Enhancements and Emerging Engg. Research.,2(3):89-91.

Kirtiar K.R. and Basu B.D. (1994).Indian Medicinal Plants, Edn 2,Vol.I,Dehradun 314-317.

Kirtikar K.R. and Basu B. D. (1980). Indian Medicinal Plants, 2nd Ed., Vol.1, Bishen Singh, Mahendra Pal Singh, India,314-315.

Kumar V.(2008).Chemical examination of Abutilon indicum, Tamarixgallicaand Xanthium strumarium. Ph.D. thesis, Chemistry Department, R. H. Government (P.G.) College, Kumaun University, India.

Kuo P.C., Yang M.L., Wu P.L., Shih H.N., Thang T.D., Dung N.X (2008). Chemical constituents from Abutilon indicum, Journal of Asian natural products research.10(7):689-93.

Liu N., Jia L. and Sun Q. (2009). Chemical constituents of Abutilon indicum (L.) Sweet. Journal of Shenyang Pharmaceutical University. 26:196-197.

Macabeo A.G. and Lee C.A. (2014).Sterols and triterpenes from the non polar antitubercular fraction of Abutilon indicum,Pharmacognosy Journal.6(4):49-52.

Macabeo A.G. and Lee C.A. (2014). Sterols and triterpenes from the non polar antitubercular fraction of Abutilon indicum, Pharmacognosy Journal. 6(4):49-52

Matlawska I. and Sikorska M. (2002). Flavonoid compounds in the flowers of Abutilon indicum (L.) Sweet (Malvaceae), Acta Poloniae Pharmaceutica. 59(3):227-229.

Mhasker K.S., Blatter E. and Caius J.F.,(2000).The Indian Medicinal Plants, Sri Satguru Publications, Delhi,Vol.2, 433.

Nadakarni A.K. (1995). Indian MateriaMedica, Popular Prakashan (Pvt) Ltd., Bombay,8-932.

Nithyatharani R. and Kavitha U.S. (2018). Phytochemical analysis of the seeds of abutilon indicum, International Journal of Creative Research Thoughts. 6(1), 447-450.

Padma R. and Senthil K. (2009). Antimycotic activity of the componenets of Abutilon indicum (Malvaceae), Drug Invention Today,1(2): 137-139.

Padma R. and Senthil K.,(2009). Antimycotic activity of the components of Abutilon indicum (Malvaceae). Drug Invention Today,1(2):137-139. 
Pandey D., Rather M., Nautiyal D. and Bachheti R. (2011). Phytochemical analysis of Abutilon indicum, International Jouranl of Chemtech Research. 3(2):642-645.

Paranjape A.N. and Mehta A.A. (2006). A study on the clinical efficacy of Abutilon indicum in the treatment of bronchial asthma, Oriental Pharmacy Experiment Med.6(4): 330-335.

Paranjape A.N. and Mehta A.A.,(2008). Investigation into the Mechanism of Action of Abutilon indicum in the Treatment of Bronchial Asthma. Global J.Pharmacol., 2(2): 23-30.

Porchezhian E. and Ansari S. H., (2005). Hepatoprotective activity of abutilon on experimental liver damage in rats. Phytomedicine, 12: 62-64.

Prabhuji S., Singh D.K., Srivastava A.K. and Rahul S.(2010). Antifungal activity of a new steroid isolated from Abutilon indicum (L.).,Medicinal Plants. 2(3):215-218.

Prajapati N.D., Purohit S.S., Sharma A.K. and Kumar T.I. (2003). A Handbook of Medicinal Plants, Edn.I, AgrobiosPublication ,Jodhpur, India

Rahuman A.A., Gopalakrishnan G., Venkatesan P. and Geetha K. (2008). Isolation and Identification of mosquito larvicidal compound from Abutilon indicum(Linn.) sweet. Parasitology Research.102(5):981-988

Rahuman A.A., Gopalkrishnan G.,Venkatesan P.and Geetha K. (2008). Isolation and identification of mosquito larvicidal compound from Abutilon indicum (Linn.) Sweet, Parasitol Res.102: 981-988.

Rajalakshmi P.V, Senthil K.K. (2009). Direct HPLC analysis of Quercetin in exudates of abutilon indicum (Linn.), J. Pharma. Science Tech.,l(2): 8083.

Rajput A. and Patel M. (2012). Chemical investigation and biological activity of phytoconstituents from methanol extract of Abutilon indicumleaves. Journal of Chemical and Pharmaceutical Research. 4(8):3959-3965

Rajput A. P., Patel M. K., (2012). Isolation and characterization of phytoconstituents from the chloroform extract of Abutilon indicum leaves (Family: Malvaceae). Asian Journal of Research in Chemistry. 5(11):13751380.

Rajurkar R., Jain R., Matake N., Aswar P. and Khadbadi S.S., (2009). Antiinflammatory Action of Abutilon indicum(L.) Sweet Leaves by HRBC Membrane Stabilization. Research Journal of pharmacy and Technology,2(2) 415-416.

Rajurkar Ravi, Jain Ritesh, Matake Narendra, Aswar Prshant andKhadbadi S.S., (2009). Anti-inflammatory Action of Abutilon indicum (L.) Sweet Leaves by HRBC Membrane Stabilization., ResearchJ. Pharm. And Tech. ;2(2):415-424.

Roshan S., Ali S., Khan A., Tazneem B. and Purohit M.G. (2008). Wound Healing activity of AbutilonIndicum.Pharmacog Mag.4(15): 85-88.

SaraswathiR. ,Upadhyay L. ,Venkatakrishnan R. and MeeraR.and Devi P. (2011). Phytochemical investigation, analgesic and anti-inflammatory activity of Abutilon indicumLinn.Int J Pharm Pharm Sci., 3(2):154-156.

Seetharam Y.M., Chalageri G., RamachandraSetty S. and Bheemachar. (2002). Hypoglycemic activity of Abutilon indicum leaf extracts in rats.Fitoterapia.73: 156-159.

Sharma A., Sharma R. and Singh H. (2013). Phytochemical and Pharmacological Profile of Abutilon Indicum L. Sweet: A Review. International Journal of Pharmaceutical Sciences Review and Research 20(1):120-127.

Sharma P.V., Ahmad Z. A. (1989). Two sesquiterpene lactones from Abutilon indicum. Phytochemistry.28 (12):3525.

Singh D. and Gupta R.S.(2008). Modulatory influence of Abutilon indicum leaves on hepatic antioxidant status and lipid peroxidation against alcohol-induced liver damage in rats. Pharmacology online.1:253 262.

Subramanian S.S. and Nair A. (1972). Flavonoids of four Malvaceous plants, Phytochemistry.11(4):1518-1519.

Thongsiri P.,(2001). Anti-diabetic activity of Thai medicinal herbs in normal and streptozotocin-diabetic rats (M.S.thesis). NakornPathom: Faculty of Graduate studies, Mahidol University, Thailand.

Tiwari Sidharth, Mishra Saumya, Misra Dharm Raj and Upadhyay Richa.,(2016). Identification of New Bioactive Compounds from Fruit of Abutilon indicumthrough GCMS Analysis, Biological Forum .An International Journal. 8(1):548-554

Vadnere G.,Pathan A. and Kulkarni B. (2013). Abutilons Indicum Linn A Phytopharmacological Review. International Journal of Research in Pharmacy and Chemistry.3(1):153-156.

Vaghasiya Y. and Chanda S. (2007). Screening of methanol and acetone extracts of fourteen Indian medicinal plants for antimicrobial activity.TurkJ. Biol.:31:243-248.

Vairavasundaram R.P. and Senthil K. .(2009). Antimycotic activity of the components of Abutilon indicum (Malvaceae).Drug Invent Today $.1(2): 137-139$

Yasmin S. (2008). Studies on bioactive natural products of selected species of family Malvaceae. Ph. D. thesis, Chemistry Department, Government College, Lahore University, Pakistan.

2020| Published by ® Plantae Scientia 